\title{
Methodology for the development of innovation projects on the basis of competitiveness indexes
}

\author{
Ekaterina Maslyukova ${ }^{1, *}$, Yuliya Anoshina ${ }^{1}$, Almaz $_{\text {Khakimov }}{ }^{2}$, Maxim Aleksandrovskiy ${ }^{3}$ \\ ${ }^{1}$ Moscow state University of technology and management. K.G. Razumovsky, Zemlyanoy Val street, \\ 73, Moscow, 109004, Russia \\ ${ }^{2}$ Sankt-Petersburg State Economic University, 21, Sadovaya street, St. Petersburg, 191023, Russia \\ ${ }^{3}$ Moscow State University of Civil Engineering, 129337, Yaroslavskoye shosse, 26, Moscow, Russia
}

\begin{abstract}
This paper presents the results of research in the field of developing innovation projects on the basis of the identification of factors of competitiveness. The principles of formation of competitiveness, including the principle of systematicity, goal-setting, efficiency, adaptability, uncertainty, and innovativeness, are substantiated. A model for the development of a competitive innovation project based on an analysis of external and internal factors providing competitive advantages is proposed. As a result of the research, an integral index of competitiveness of innovation projects was formed, characterizing the level of innovation achieved and allowing substantiating the directions for further development of investment and construction projects.
\end{abstract}

\section{Introduction}

Nowadays, innovations are strategically important and in many ways determine the competitiveness, efficiency, and development of the economy of the enterprise, the region, and the country as a whole. Implementation of scientific and technical achievements in the production of new goods, technologies, and services is of decisive importance for improving the standard of living of the population, contributes to higher labor productivity, the creation of new industries, services and jobs, improving the quality of services and increasing the competitiveness of domestic goods on the world market.

The most common form of introducing innovations is the implementation of innovation projects that represent a complex system of interdependent and interrelated by resources, terms and implementers activities aimed at achieving specific goals in the priority areas of science and technology development. The effectiveness of projects is largely determined by the perfection of the system of selection of innovations for implementation and their adaptation to the existing and changing in time conditions of the economy [1].

A dynamic market environment has a strong impact on the need to identify and implement opportunities to create and maintain the competitive advantages of innovation projects. Issues of competitiveness are among the most difficult, because they based on a

*Corresponding author: maslyukova@mail.ru 
multivariate, multi-criteria assessment of a number of factors and trends often acting in different directions. The analysis of the impact of both economic and non-economic factors at all stages of the life cycle of the innovation project, from the search for new ideas to their use, commercialization and spreading, will allow controlling its competitiveness [2].

However, up to now, a number of theoretical and practical issues in the field of innovation management have not been systematized and ordered. A significant increase in the number of innovation projects in modern market conditions requires serious scientific research and recommendations to ensure their competitiveness, the analysis of existing methods of assessment, the formation of basic principles for the development, and sequencing stages of implementation. Strengthening the competitive advantages of any project is directly dependent on the correct choice of the type of innovations in its composition and methods of managing their life cycle.

\section{Materials and methods}

Innovation project is associated with the creation, development, and spreading of innovations. In the conditions of the market, producers of products or services are constantly forced to seek ways to reduce production costs and enter new markets, and organizations that have first mastered effective innovations gain a significant advantage over their competitors. Innovation is the final result of introducing novelty in order to improve the management object and to obtain an economic, social, ecological, scientific and technical, or other kind of effect. Innovation project is a broader concept and can be viewed from various positions and with various level of specification [3].

First, it represents the implementation of research, scientific and technical, actually innovative, production activities and marketing. Secondly, it can be understood as stages of the life cycle of innovation from the origin of the idea to its development and spreading. Third, from a financial point of view, it can be viewed as a process of financing and investing in the development and distribution of a new type of product or service.

In general, an innovation project consists in obtaining and commercializing an invention, new technologies, types of products and services, industrial, financial, administrative or other decisions and other results of intellectual activity.

A key role in the formation of an innovation project at the present stage is played by its competitiveness. The competitiveness of an innovation project is a dynamic property that characterizes its ability to be implemented in a competitive market and reflects the attractiveness of the project both for the consumer and for investors, as determined by the degree of its economic efficiency [4].

An analysis of all the above provisions made it possible to identify the main factors of a competitive innovation project, in accordance with which a number of principles for its development were proposed (Figure 1).

On the basis of the above, the following can be attributed to the principles of developing a competitive innovation project [5].

1. The principle of goal-setting - involves determining not only the main goal of the project but also a set of sub-goals, and the decisions made are assessed in terms of their optimal combination. This principle facilitates the establishment of interrelations between the needs for creating innovations and the opportunities for their implementation.

2. The principle of systematicity, in which the innovation project is viewed as a complex dynamic system, which includes interrelated elements. Systemic management of the competitiveness of the innovation project is to provide the control effect on the stages of the life cycle of innovations included in the project, ensure the formation, maintenance, and development of its competitive advantages in a competitive market environment determined by a high degree of uncertainty and volatility. 


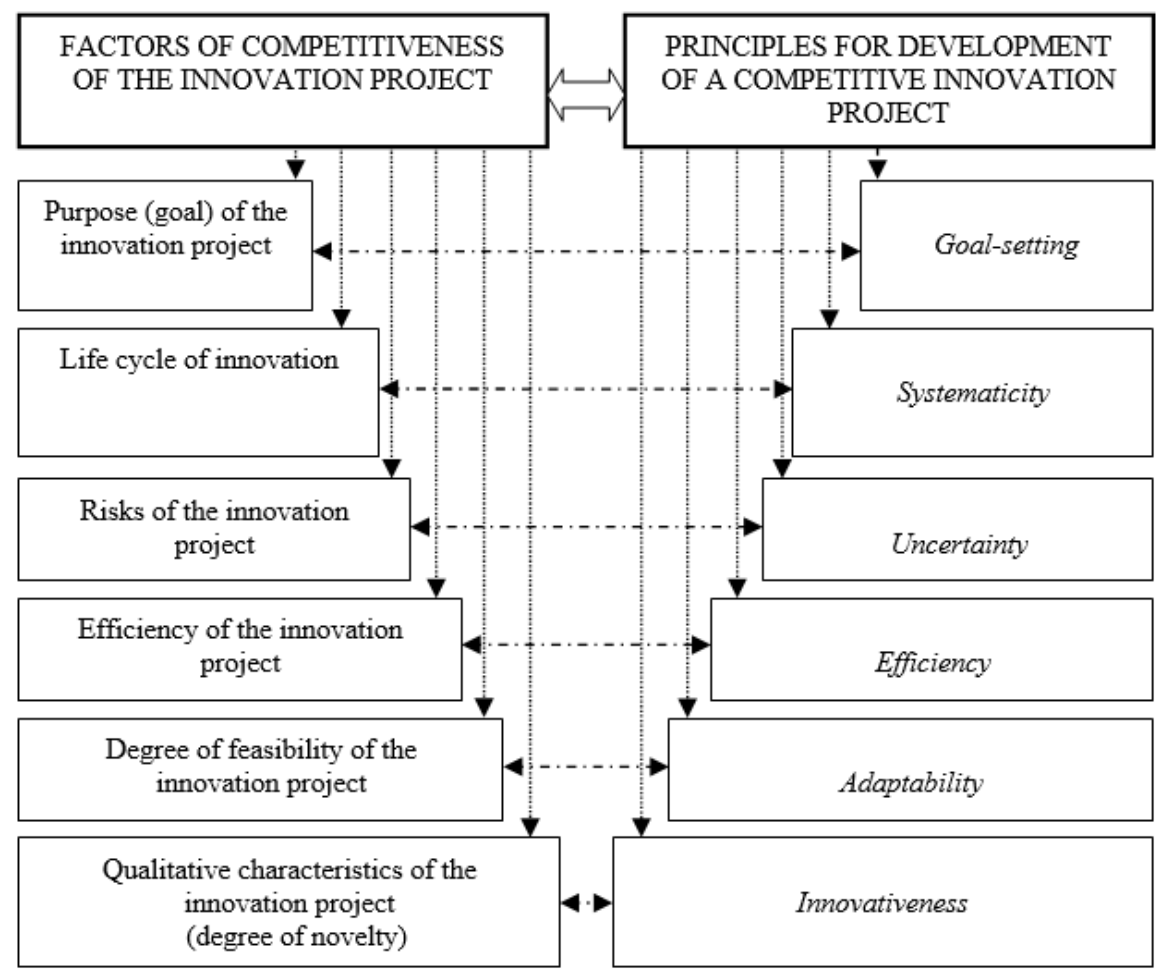

Fig. 1. Factors of competitiveness of the innovation project.

3. The principle of uncertainty that takes into account the systematic and random factors that affect the process. Ignoring of the random factors reduces the reliability of the analysis. 4. The principle of efficiency that involves choosing an innovation project with minimum costs to achieve a long-term planned result, which means an increase in efficiency with all other things being equal.

5. The principle of adaptability that involves the implementation of an innovation in accordance with the capabilities of the economic and innovation environment.

6. The principle of innovativeness that involves ensuring the novelty of the innovation being introduced.

\section{Results}

Based on the principles of a competitive innovation project, a model is proposed that allows developing and implementing economically substantiated and competitive innovation projects (Figure 2).

When implementing this model, a sequence of states of the innovation project is formed depending on the life cycle of its innovations, which allows transition from the existing characteristic point of development to the desired one. This substantiates the necessary processes, which must be activated to implement these states. The transition from the current state to the desired one occurs when the project portfolio is realized: it is necessary to assess the entire set of planned innovations, determine the state of the market that needs to be achieved, select and form the portfolio of the innovation project, and continuously monitor its level of competitiveness. The model allows forming the maximum possible 
competitiveness of an innovation project based on the linking of several innovations and reflects the sequence of states of innovation processes [6].

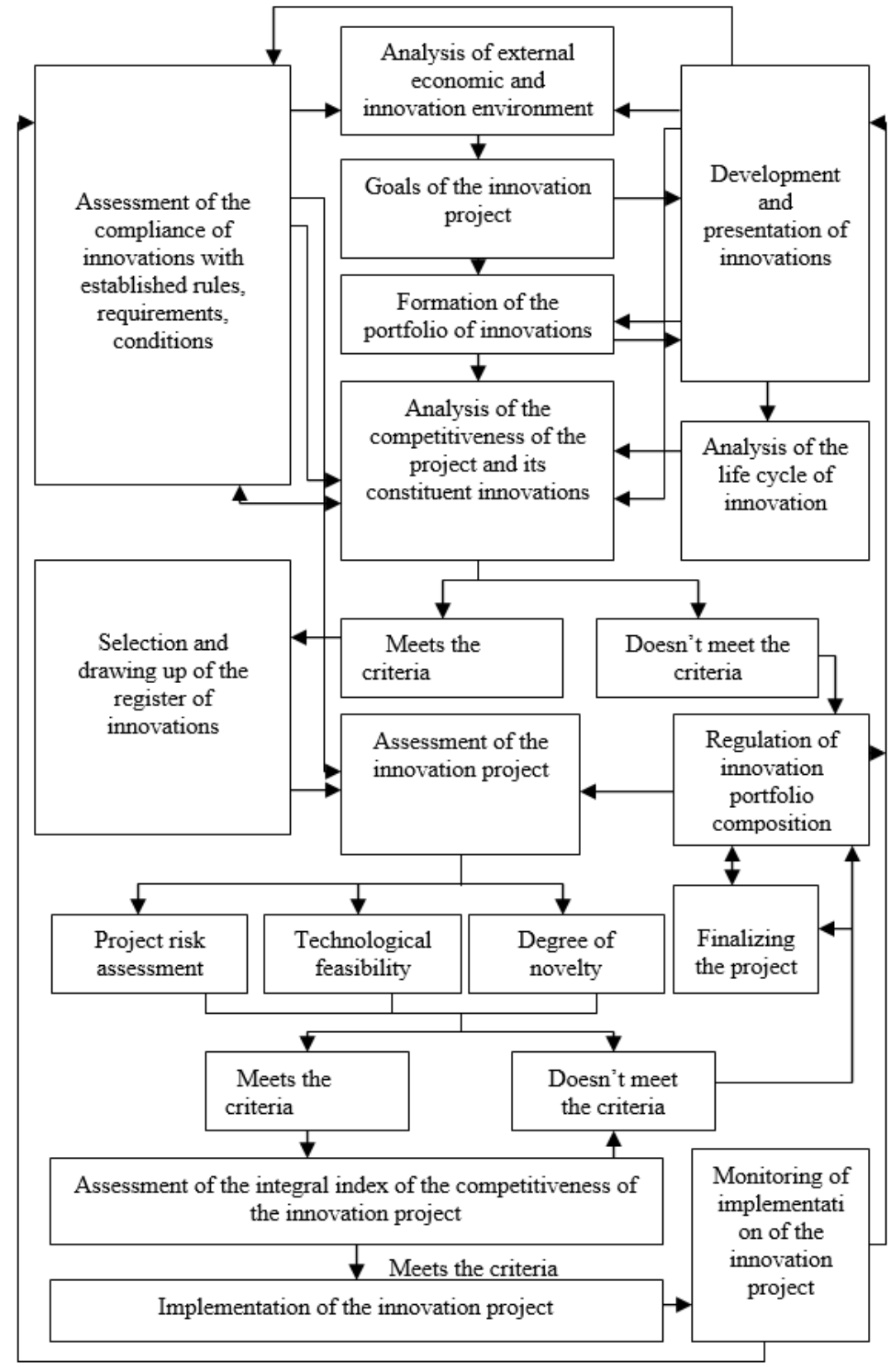

Fig. 2. Model of the development of a competitive innovation project.

The analysis of the factors used to find the integral index of the competitiveness of innovation projects makes it possible to identify the strengths and weaknesses in the development of the innovation activity of the country, region, industry, or enterprise and the implemented strategy of innovative development. On the basis of a factor analysis of the indexes included in its composition, the generalizing index of the competitiveness of innovation projects allows proposing measures for the development of the innovation 
sphere as a part of economic modernization and innovative development aimed at economic growth and increasing the cash flow [7].

Multifactorial correlation analysis was carried out on the basis of experimental data of 20 innovation projects. At the first stage, factors were determined for the correlation analysis, and those ones that had the most significant impact on the competitiveness index under study were selected. At the second one, the initial information necessary for the correlation analysis was assessed; at the third one, the character was studied, and the relationship between factors and performance indicators was modeled; at the fourth stage, the calculation of the main correlation indicators of the correlation analysis was done; at the fifth one, a statistical assessment of the results of the correlation analysis and their practical application is made [8].

Based on the studied groups of factors, an equation for assessing the competitiveness of the project was proposed:

$$
K=11,3+0,37 X_{1}+0,21 X_{2}+8,6 X_{3}
$$

where $\mathrm{X} 1 \ldots \mathrm{X} 3$ - are assessed as follows (Table 1).

The integral index $\mathrm{K}$ makes it possible to predict the competitiveness of an innovation project depending on the changes in the presented groups of factors.

Analyzed innovation projects are divided into the following groups:

Group 1 - an integral index above 2.25 - innovation projects with high competitiveness;

Group 2 - an integral index from 1.75 to 2.25 - innovation projects with an average level of competitiveness;

Group 3 - an integral index below 1.75 - innovation projects with a low level of competitiveness.

Table 1. Assessment of factors of competitiveness.

\begin{tabular}{|c|l|l|}
\hline $\begin{array}{c}\text { Regression } \\
\text { coefficient }\end{array}$ & \multicolumn{1}{|c|}{$\begin{array}{c}\text { Group of factors of } \\
\text { competitiveness }\end{array}$} & \multicolumn{1}{c|}{ Indicators of competitiveness assessment } \\
\hline$X_{I}$ & $\begin{array}{l}\text { Competitiveness of } \\
\text { innovation }\end{array}$ & $\begin{array}{l}\text { the sum of the following indicators }(0-\text { "no", } 1- \\
\text { "yes"): availability of analogues; market } \\
\text { availability; high quality; advertising; reputation; } \\
\text { affordable price. }\end{array}$ \\
\hline$X_{2}$ & $\begin{array}{l}\text { Efficiency of project results } \\
\text { for investors }\end{array}$ & $\begin{array}{l}\mathrm{Fu}=\mathrm{P} / \mathrm{Pr} \\
\mathrm{P}-\text { earnings before interest and taxes; } \\
\mathrm{Pr}-\text { percentage to be paid }\end{array}$ \\
\hline$X_{3}$ & $\begin{array}{l}\text { Quality of project } \\
\text { management (quality of } \\
\text { management process) }\end{array}$ & $\begin{array}{l}\mathrm{U}=\mathrm{J}^{*} / \mathrm{J} \\
\mathrm{J}^{*}-\text { the number of intellectual property objects } \\
\text { brought to implementation; } \\
\mathrm{J}-\text { total number of objects of intellectual property }\end{array}$ \\
\hline
\end{tabular}

On the basis of a data combination, the integral index allows simultaneously analyzing the level of competitiveness of an innovation project with obtaining sufficiently reliable results. The result of the assessment of factors and the calculation of the integral index serve as final indicators that focus attention on the main problems of ensuring the competitiveness of the innovation project and help to correct the identified inconsistencies in time [9].

\section{Discussion}

The application and use of an integral index of the competitiveness of an innovation project allows us: 
- first, to identify the strengths and weaknesses in innovative development and in the development of certain spheres that directly influence the activation of innovation activity;

- secondly, to identify the factors that have the greatest impact on the development of the innovation environment and the activation of innovation process;

- thirdly, to develop recommendations on the directions of innovative development of economic entities.

Thus, on the one hand, the integral index of the competitiveness of the innovation project reflects and characterizes the level of innovation opportunities achieved; on the other hand, it allows identifying the directions for further development in conditions of obtaining profit or economic effect, achieving economic growth with a high level of competitiveness of the external environment.

\section{Conclusion}

The conducted research allows us to draw a conclusion that the theoretical and methodological problems of developing scientific provisions for the formation of competitive innovation projects based on an analysis of external and internal factors are of great economic importance, and the solution of these issues is very relevant. The wide introduction of innovation projects, the continuous creation of new combinations of production factors have become the norm of modern economic life.

Based on the conducted analysis, factors of competitiveness of the innovation project are revealed and the main principles of its implementation are substantiated.

The proposed model for the development of a competitive innovation project is based on managing the parameters of their life cycle and involves the use of the results of an analysis of external and internal competitive advantages. In turn, this allows maintaining a constant growth of the innovation potential of the project due to the phased implementation of several innovations and an increase in the life cycle of the project.

\section{References}

1. A. Larionov, E. Nezhnikova, International Journal of Applied Engineering Research 6, 4433-4439 (2016)

2. A. Jones, G. Fallon, R. Golov, European Business Review 12(4), doi:10.1108/09555340010336871

3. E. Nezhnikova, R. Obukhov, MATEC Web of Conferences 106, 08025 (2017) https://doi.org/10.1051/matecconf /201710608025

4. V. Pukhkal, V. Murgul, M. Garifullin, Procedia Engineering 117, 624-627 (2015)

5. A. Bril, O. Kalinina, O. Valebnikova, Lecture Notes in Computer Science 9870, 766775 (2016) doi: 10.1007/978-3-319-46301-8_67

6. A.K. Orlov, I.Y. Chubarkina, MATEC Web of Conferences 08015, 106 (2017)

7. B. Marchi, S. Zanoni, M. Pasetti, A techno-economic analysis of Li-ion battery energy storage systems in support of PV distributed generation, 21st Summer School F. Turco of Industrial Systems Engineering, 13-15 September, 2016, Naples, Italy (2016).

8. I. Lukmanova, M. Mishlanova, International Journal of Economics and Financial Issues 5, 208-216 (2012)

9. V. Gasilov, N. Anisimova, N. Provotorov, MATEC Web of Conferences 106, 08035 (2017) DOI: 10.1051/ mateconf / 201710608035 